\title{
Application of HFPSO-TOPSIS approach for optimally locating and sizing of reactive power compensating devices for voltage control ancillary service
}

\author{
Kalyani Kurundkar ${ }^{\mathbf{1}}$ and Dr. G.A.Vaidya ${ }^{\mathbf{2}}$ \\ ${ }^{1,2} \mathrm{PVG}$ 's COET and GKP(W)IOM, India \\ *Correspondence: Kalyani Kurundkar; Email: Kalyani.kurundkar@ gmail.com
}

\begin{abstract}
Modern power system with renewables in distribution network has made the optimal sizing and location of reactive power support crucial and essential. By optimal locating and sizing of reactive power support resources causes a pow er loss reduction, improvement in voltage profile and maximizes techno-economic benefits to consumers and system operators while improving overall system performance and reliability. However, the optimal location of the reactive power supporting device (OLRPSD) and its sizing for voltage control ancillary service is a multi-objective problem requiring a multi-objective multicriteria decision-making (MOMCDM) approach. In literature, objectives of reactive power supporting have been to minimize the power losses. But it has more than one objective that depends upon the reactive power supporting device. Moreover, the economic benefit from reactive power support also requires to be considered, which is of utmost importance for all stakeholders. In this paper, OLRPSD is performed considering financial benefit by an objective of reactive power cost minimization along with other targets like power loss reduction, maximization stability margin of voltage, and minimization of deviation of voltage with an application of a recently developed MOMCDM technique known as Hybrid Firefly Particle Swarm Optimization with TOPSIS approach (HFPSO-TOPSIS) and is therefore new. This is executed on "modified IEEE 33 bus" radial distribution network. Various reactive power compensating devices considered are Distributed generation (DG's), Batteries, capacitors and DSTATCOM and Electric vehicle charging stations. The results show the merit of this method over the existing ones.
\end{abstract}

Keywords: Hybrid Firefly Particle Swarm Optimization, TOPSIS, multi-objective, reactive power support, voltage control ancillary service.

\begin{tabular}{|c|c|}
\hline \multicolumn{2}{|l|}{ ARTICLE INFORMATION } \\
\hline \multicolumn{2}{|c|}{$\begin{array}{l}\text { Author(s): Prof. Kalyani Kurundkar, Dr. G.A.Vaidya } \\
\text { Received: } 22 \text { Oct, 2021; Accepted: } 04 \text { Nov, 2021; Published: } 17 \text { Dec, 2021; }\end{array}$} \\
\hline $\begin{array}{l}\text { e-ISSN: } 2347-470 X ; \\
\text { Paper Id: IJEER-2021-07; }\end{array}$ & Crossef member \\
\hline $\begin{array}{l}\text { Citation: doi.org/10.37391/IJEER.090301 } \\
\text { Webpage-link: }\end{array}$ & $\begin{array}{l}\text { CROSSREFOORG } \\
\text { THECTIATOOULNKNG BACKBONE }\end{array}$ \\
\hline
\end{tabular}

\section{INTRODUCTION}

Modern restructured Power systems having distributed generation (DG's) with bidirectional power flow has made it imperative to have reactive power support. This support is required in the form of reactive power reserves is essential for voltage control and stability of network. Compensation of Reactive power is one of the critical ancillary services essential to support the grid operations i.e. smooth delivery of power from generation to load. Smart Grid technology has enabled new technologies for providing reactive power support at transmission and distribution levels.

India is not behind in reducing carbon emissions through renewable energy inclusion in generation $\operatorname{mix}$ and implementation of its smart grid road map. India is planning to have 100 smart cities and have made considerable investment in this direction. Similar to different countries of the world like Australia, Sweden, the U.K, U.S.A, Denmark, India has also made amendments in many regulations for including Renewables in Indian Electricity generation mix from the past few years. There are strategic plans to have $450 \mathrm{GW}$ of electricity from renewable still 2030 [1]. All such circumstances have increased the need to maintain voltage at distribution level also in limits. In India, accordingly, there will be a rise in reactive power supporting the market by 2020 . It has reached to about 20 million.

This market sizing is done on three different bases [2]

1. Customer basis i.e. industries, utilities, railways, NTPC and big manufacturing industries [2].

2. Type of load: slow varying loads such as servers, escalators, distribution transformers, fast changing loads like traction system, elevators and industrial loads, very fast changing loads like spot welding, arc furnaces, rolling mills etc.

3. Reactive power compensating devices: D-STATCOM, dynamic voltage restorer, DVR's, fixed or variable Capacitors etc.

Uncertainty of generation from renewable sources and irregular demand causes increase or decrease in power factor and therefore reactive power support becomes necessity. Any change in voltage level is controlled by efficient and effective use of reactive power compensating devices. By optimal location of reactive power supporting devices in the network, voltage stability is also enhanced.

- The introduction should briefly place the study in a broad context and highlight why it is important. It should define the purpose of the work and its significance. The current state of the research field should be reviewed carefully and key publications cited. Please highlight controversial and diverging hypotheses when necessary. Finally, briefly mention 
the main aim of the work and highlight the principal conclusions. As far as possible, please keep the introduction comprehensible to scientists outside your particular field of research. References should be numbered in order of appearance and indicated by a numeral or numerals in square brackets, e.g., [1] or [2-3], or [4-6]. See the end of the document for further details on references.

\section{LITERATURE}

(OLRPSD) at the distribution level is a complex problem as it has various factors to be considered [3]. First is the location of resources and cost of reactive power, which differs along with the location. Second is an identity of sources for reactive power supporting devices other than synchronous condensers, such as D-STATCOM, DVR's, Capacitors, Batteries, DG's etc. Recent studies have shown that EV chargers also play an essential role for reactive power supporting at the distribution level. Therefore, various constraints are to be considered while finding out an optimal solution for this problem. But for proper implementation of reactive power supporting for voltage control ancillary service policy level changes are also required. Third factor responsible to make the OLRPSD problem more complex is changes in conventional techniques used by reactive power providers like load flow analysis that can determine the requirement of this reactive power services.

OLRPSD is a problem subject to various operating constraints of the system under consideration. This problem of OLRPSD at transmission level has been solved using Analytical, heuristic methods as well as linear programming. It is found that for this search problem Heuristic methods are best suited because they are fast, robust, converging in nature. Some of the methods used are Genetic Algorithm, Particle Swarm Algorithm, Ant colony optimization, etc. [4]. In distribution system, this problem becomes more complex especially the due to changes in topology caused by large scale integration of renewable energy sources. This research study is focused on OLRPSD in distribution grids because in the near future the distribution grid will be the network of multi-micro-grid and will experience bi-directional power flows and voltage control will be a major concern. DG's and storage systems are the vital components of micro-grids. Reactive power support is essential for loss minimization, power factor improvement, harmonic mitigation and maximum active power transfer from generation to load.

Distributed generators are optimally located particle swarm optimization (PSO) is considered in [5]. Hybrid PSO and whale optimization are implemented with single objective loss minimization functions in [6] and [7]. Research studies are focused on optimal capacitor location. Similarly, in [8], authors have considered objective of voltage improvement by considering Loss sensitivity indices, capacitor operating constraints, a minimum number of capacitors required. DSTATCOM is optimally placed in [9] using direct load flow (DLF) [10] MOGA and [11] harmony search algorithm aims for minimization of voltage deviation, losses, harmonic distortion and minimization of cost. Similarly for battery location in [12] PSO is used and GA in [13] with minimization of losses as its objective. Reactive power supporting is also possible by Electric Vehicle (EV's) Chargers i.e. charging stations play a very important role for reactive power supporting, optimal Location of chargers in handled in [14] by teaching learning algorithm, and in [15] by PSO .

1. However, very few researchers have considered the optimal location of different reactive power supporting devices as in incorporated in this work. Therefore, OLRPSD is performed considering the optimization of reactive power keeping cost, along with all other objectives like minimization of losses, reduction in voltage deviation and voltage stability index is maximized for voltage control ancillary service at maximum load condition. This has resulted in voltage profile improvement and overall financial system operation cost reduction.

2. This type of problem requires a technique that optimizes multiple and equally important objectives. Therefore, this problem is to be solved as a Multi-Objective, Multi-Criteria Decision-Making problem (MOMCDM). This further requires to set order of preference to find the ideal solution which can be well carried out by a "Technique for Order of Preferences by Similarity to Ideal Solution (TOPSIS)" [21] approach.

In This work OLRPSD is performed considering an objective of minimization of reactive power cost for economic benefit and other equally important objectives like minimization of losses, voltage stability maximization and minimization of voltage deviation. Recently developed MOMCDM technique known Hybrid Firefly Particle Swarm Optimization with TOPSIS approach (HFPSO-TOPSIS).

This algorithm considers the advantages of both Firefly and Particle Swarm Optimization for fast convergence to find a global optimum. The TOPSIS approach is further utilized for ranking the solution according to the priorities of the objective function.

Five different reactive power compensating devices which are considered in this study are:

1. Capacitors

2. D-STATCOM with and without DG

3. Distributed generation (DG's)

4. Battery

5. Electric Vehicle Charging station

Organization of this paper is as follows: Section I gives introduction, section 2 discusses related literature section 3, explains the methodology used, section 3 discusses in detail HFPSO-TOPSIS for solving OLRPSD problem, section 4, explains base case in this study, section 5, discusses the test results of OLRPSD and section 6, gives conclusion with future scope.

\section{METHODOLOGY}




\subsection{Formulation of Problem with Objectives considered}

The multi-objective function for this OLRPSD problem is given as follows:

\subsubsection{Voltage deviation minimization:}

The system voltage quality is measured by the node voltage deviation [6]. Therefore, utilities require to maintain the node voltage in a regulated level. In the OLRPCD integration model, minimization voltage deviation at a node is considered and is expressed as

minimize $f_{1}=\sum_{d=1}^{\mathbb{d}}\left(V_{d}-1\right)^{2}$

Where, voltage at node ' $\mathrm{d}$ ' is $V_{\mathbb{d}}$, total number of nodes ' $\mathrm{Nd}$ ' in network.

\subsubsection{Minimization of losses:}

In distribution network maximum power loss occurs due to during power delivery that causes maximum revenue losses to the utility. If losses are less than power delivery with good voltage levels is possible [5, 6] Second objective is power loss minimization for OLRPSD, which may be expressed as

$\min f_{2}=\sum_{i=1}^{N d} \sum_{j=1}^{N d} \gamma_{i j}\left(P_{i} P_{j}+Q_{i} Q_{j}\right)+p_{i j}\left(Q_{i} P_{j}+P_{i} Q_{j}\right)$

Where

$\gamma_{i j}=R_{i j} \cos \left(\delta_{i}-\delta_{j}\right) / V_{i} V_{j}$

$\rho_{i j}=R_{i j} \sin \left(\delta_{i}-\delta_{j}\right) / V_{i} V_{j}$

' $\mathrm{Nd}$ ' is number of nodes in total, $\mathrm{P}_{\mathrm{i}}$ is active and $\mathrm{Q}_{\mathrm{i}}$, is reactive power injections at the ' $i$ ' node, resistance $R_{i j}$ is between node ' $\mathrm{i}$ ' and node ' $\mathrm{j}$ ', ' $\mathrm{V}_{\mathrm{i}}$ ' is voltage magnitude and $\delta_{\mathrm{i}}$ is angle of the $i^{\text {th }}$ node and at node ' $\mathrm{j}$ ', ' $\mathrm{P}_{\mathrm{j}}$ ' is active and ' $\mathrm{Q}_{\mathrm{j}}$ ' is reactive power injections.

\subsubsection{Reactive power supporting Cost minimization:}

The reactive power cost from reactive power supporting devices is minimized [16].

$\min f_{a}=\sum_{i=1}^{n} \operatorname{Cost}\left|Q_{d}\right| \geq 0$

This cost covers the device's purchase price as well as installation and maintenance charges. The reactive power supporting value in MVAr at node ' $\mathrm{d}$ ' is ' $Q_{d}{ }^{\prime}$, and ' $\mathrm{n}$ ' is number of network nodes.[17] gives the costing of reactive power from Capacitors, D-STATCOM, DG's, batteries and EV charging stations. While considering the fourth objective function the cost per MVAr for each device depends upon installation and maintenance cost for devices like capacitor, DSTATCOM etc. For cost calculations from DG opportunity cost has to be considered along with investment and maintenance cost. The investment and maintenance cost for reactive power supporting devices are considered as in [17] when installed in distribution grids, which must be analysed together with the saving of revenue gained by energy loss reduction. Costing of reactive power from devices providing reactive power support is considered in $f_{a}$ objective function.
For reactive power cost from capacitor and D-STATCOM reactive power costing:

$$
\operatorname{Cost}\left(Q_{\text {React }_{G i}}\right)=\operatorname{Cost}\left(S A_{G \max }\right)-\sqrt{\operatorname{Cost}\left(S A_{G \max }^{2}-Q_{\text {React }_{G i}^{2}}\right) * k}
$$

Where,

$\mathrm{Q}_{\text {ReactGi }}=$ reactive power,

$\mathrm{SA}_{\mathrm{Gmax}}=$ Maximum Nominal Apparent Power, $\mathrm{K}=$ rate of benefit from active power generation, ${ }^{k}$ is considered as $10 \%$ in the paper work.

The reactive power cost from DGs i.e. its cost function, for the reactive power support, becomes:

$$
C\left(P_{D G}, Q_{D G}\right)=C_{D G}^{Q}\left(P_{D G}, Q_{D G}\right)+C_{D G}^{0} \times Q_{D G}^{\max }
$$

Where $C_{P V}^{0}$ is the fixed cost in per unit that the DG will spend on change in size of converter for incorporating reactive power supporting feature and $Q_{P V}^{\max }$ is the maximum capacity of the converter [17].

$$
C_{P V}^{Q}\left(P_{D G}, Q_{D G}\right)=F_{e e d I T_{D G}} \times \Delta \operatorname{Loss}_{D G}\left(P_{D G}, Q_{D G}\right)
$$

Where ${ }^{F e e d I T_{D G}}$ is the rate of feed-in tariff for any DG power produced by renewable source and its payment in per $\mathrm{kWh}$ and

$\Delta \operatorname{Loss}\left(P_{D G}, Q_{D G}\right)=$ converter losses.

\subsubsection{Voltage stability margin (VSM) Maximization:}

The voltage stability Margin (VSM) is maximized to keep the system stable. This is achieved by minimizing the Voltage stability indices (VSI). VSI is a level of device protection that describes a node's ability to keep its voltage profile within acceptable bounds under a variety of high loading scenarios The VSIs of the branch connecting nodes a and by [6 ], [20].

$V S I_{a b}=V_{b}^{4}-4\left(P_{a} x_{a b}+Q_{a} x_{a b}\right) V_{b}^{2}-4\left(P_{a} x_{a b}-Q_{a} x_{a b}\right)^{2}$

Where impedance $x_{a b j}$ is that of branch connecting nodes a and $\mathbf{b}$. The objective function for can be expressed as:

maximize $f_{4}=\min \left(V S I_{i j}\right) \quad \forall \forall_{i, j}$

\subsection{Basic Constraints}

The following constraints are considered along with some special constraints that vary as per the devices. The fundamental power flow equality and inequality constraints followed while solving this problem are:

- Power Balance Constraint: power balance equations at node ' $\mathrm{a}$ '. $\mathrm{P}_{\mathrm{a}}$ is the active power and $\mathrm{Q}_{\mathrm{a}}$ is the reactive power at node 'a' [6].

$$
P_{a}=V_{a} \sum_{b=1}^{N d} V_{b} Y_{a b} \cos \left(\theta_{a b}+\delta_{b}-\delta_{a}\right) \quad \forall a
$$




$$
\begin{aligned}
Q_{a} & = \\
& -V_{a} \sum_{b=1}^{N d} V_{b} Y_{a b} \sin \left(\theta_{a b}+\delta_{b}-\delta_{a}\right) \forall a
\end{aligned}
$$

\subsubsection{Bus voltage constraint [6]:}

At each bus, if the voltage is (Va) it must be within their minimum voltage and maximum voltage limits as:

$V_{a}^{\min } \leq V_{a} \leq V_{a}^{\max }$

\subsubsection{Constraint for Power flow [5] [6]:}

In each line, the power flow in $\left(\mathrm{PF}_{\mathrm{K}}\right)$ should be lesser than the line's maximum limit of power flow $\left({ }^{P F_{K}^{\max }}\right)$ as:

$$
\left|P F_{K}\right|<P F_{K}^{\max }
$$

\subsubsection{Overall power factor constraint $[6,8,10,12]$ :}

The power factor of the system $\left({ }^{p f_{s y s}}\right)$ must be greater than

$\left({ }^{p f_{s y s}^{\min }}\right)$ i.e. the minimum of its value as:

$$
\left|p f_{s y s}\right| \geq p f_{s y s}^{\min }
$$

More device specific constraints that are followed for optimal capacitor, D-STATCOM, and DG's.

\subsection{Device specific constraints}

\subsubsection{Capacitor constraints:}

Along with General operational constraints these constraints are followed for optimal capacitor location [8].

\subsubsection{Number of Capacitor Constraint:}

' $\mathrm{N}_{\text {Cap }}$ ' is the number of capacitors that must be equal to or lesser than the highest number of potential locations $\left(N l_{c a p}^{\max }\right)$, this will reduce cost significantly.

$$
N_{\operatorname{Cap}} \leq N l_{\operatorname{cap}}^{\max }
$$

3.3.3. Constraint on size of Capacitor:

Size of capacitor for reactive power injections in the system must be limited by bounds.

$$
Q_{c_{j}}^{\min } \leq Q_{c_{j}} \leq Q_{c_{j}}^{\max }
$$

Where, reactive power injection at node $f$ is $Q_{c_{j}}$.

\subsubsection{Constraint for reactive power support from capacitor:}

Reactive power from load ( $\left.Q_{\text {Load }}^{\text {Total }}\right)$ should be greater than $Q_{\text {Cap }}^{\text {Total }}$ i.e. reactive power contribution from capacitor

$$
Q_{\text {Cap }}^{\text {Total }}<Q_{\text {Load }}^{\text {Total }}
$$

\subsubsection{Constraints for D-STATCOM:}

Along with General operational constraints these constraints are for D-STATCOM location and sizing [9] [10] [11].
Minimum limit of reactive power supporting is $Q_{\text {Dstatmin }}(t)$ at bus ' $t$ ' and $Q_{\text {Dstatmax }}(t)$ is the maximum limit of reactive power supporting at bus ' $t$ '.

\subsubsection{Constraints for DGs:}

Along with General operational constraints these constraints are followed for DG Location [5] [6][7]:

$$
\begin{array}{ll}
D G_{i}^{\min } \leq D G_{i} \leq D G_{i}^{\max } & \forall i \\
\sum_{j=1}^{W} \alpha_{i} D G_{i} \leq D_{p e a k} & \forall i
\end{array}
$$

Where, $D G_{\mathrm{i}}^{\min }{ }_{\text {, }} D G_{\mathrm{i}}^{\max }$ is the smallest and largest size of DG located on one node, DG installation decision variable is $\alpha_{i}$ at node $i$, and $D_{\text {peak }}$ is the network peak demand.

\subsubsection{Constraints for batteries:}

For optimal Battery location along with general operational constraints [12, 13].At instant ' $t$ ' the battery bank should satisfy following constraints:

$$
\begin{aligned}
& E_{\text {Battmin }}(t)=(1-D O D) * S_{\text {Batt }} \\
& E_{\text {Battmin }}(t) \leq E_{\text {Batt }}(t) \leq E_{\text {Battmax }}(t)
\end{aligned}
$$

Where $E_{\text {Battmax }}(t)$ is battery's maximum charge quantity, $E_{\text {Battmin }}(t)$ is battery's minimum charge quantity and $S_{\text {Batt }}$ is battery's capacity. $D O D$ is battery's depth of discharge and $\sigma$ is rate of Self- discharge of battery.

\subsubsection{Cons traints for EV charging stations:}

Along with General operational constraints these constraints are followed for number ' $n$ ' of EV charging station ( $C h S$ ) consisting of Charging points $(C h P)$ location subject to following constraints:

$$
\begin{aligned}
& n C h P_{\min } \leq n C h P \leq n C h P_{\max } \\
& n C h S_{\min } \leq n C h S \leq n C h S_{\max }
\end{aligned}
$$

\section{HFPSO-TOPSIS METHOD}

\subsection{Particle swarm Optimization}

In "Particle Swarm Optimization (PSO) algorithm", the particles are possible solution to the problem. Best particle, showing fitness value that is best in the solution search space and all particles are oriented towards it. The velocity of each particle (VL) is updated in each iteration, also the position is changed according to the orientation towards the best fitted particle. Equation (18) gives the position and velocity of individual particles. New changed Velocity for each particle ${ }^{J} j^{t}$, is calculated by equation (20) with past iteration position $Z_{j}$ based on its past iteration velocity $V L_{j}$.Iteratively , 
particle's local best fitness $\left(P_{\text {Best }}\right)$ and the global best particle among the neighboring particles is $\left(G_{\text {Best }}\right.$ ) is calculated by equation (20). The weights are updated as in equation (19) iteratively to get the global best solution. The ' $\mathrm{CO}_{1}$ ' and ' $\mathrm{CO}_{2}$ ' are the constants for acceleration that change the velocity of a particle towards $P_{\text {Best }}$ and $G_{\text {Best }}$ and random random $_{2}$ are uniformly distributed random numbers in [16].

$V L_{j}^{i t r+1}=\omega \cdot V L_{j}^{i t y}+c o_{1} \cdot$ random ${ }_{1} \cdot\left(P_{\text {Best } j}^{i t y}-Z_{j}^{i t y}\right)+$ $\mathrm{CO}_{2} \cdot$ random $2 \cdot\left(G_{\text {Best }}^{\text {ity }}-Z_{j}^{\text {ity }}\right)$

$Z_{j}^{i t r+1}=Z_{j}^{i t y}+V L_{j}^{i t y+1}$

$\mathrm{WT}_{\mathrm{a}}^{\text {ity }}=W T_{\max }-\left[\left(W T_{\max }-W T_{\min }\right) / i r_{\max }\right] *$ itr

\subsection{Firefly Algorithm}

"Firefly algorithm (FA)" works on fireflies' behavior of bioluminescence. Depending upon the brightness of each firefly they are attracted towards each other. The attractiveness of the fireflies is ' $\beta_{0}$ '. If brightness is more the distance between the fireflies will be less. Let ' $i$ ' and ' $j$ ' be the two fireflies with distance between the two fireflies is ' $r_{i j}$ ' and position is ' $Z$ '. The by the scaling factor $\alpha$ is between and $\epsilon$ $(0,1)$ controls the movement as well as randomization of fireflies. The luminance of a firefly depends on objective function. Visibility is controlled by ' $\gamma$ ' and is between $(0, \infty)$. This process goes on iteratively, till the best solution is reached or maximum number of iteration are reached. $\in i$ is random variables vector.

$Z_{i}^{i t y+1}=Z_{i}^{i t y}$
$\omega \epsilon_{i}^{i t y}$

\subsection{Hybrid Firefly-Particle Swarm Optimization}

Ibrahim Berkan designed "Hybrid firefly and particle swarm optimization (HFPSO)." This algorithm maintains balance between global level optimal solution as well as local level optimal solution taking into account strong points and advantageous features of both "Firefly algorithm (FA) and Particle Swarm Optimization algorithm". There is no velocity parameter in firefly algorithm or no recorded individual best position $\left(P_{\text {Best }}\right)$. PSO is commonly utilized in the global search in these two algorithms because it converges rapidly in exploration and FA is also commonly employed in local search i.e exploitation. The HFPSO takes initial input parameters, these parameters are used as per requirement by both the algorithm. Further randomly uniform particle vectors are generated in the search space which is pre-defined along with predefined velocity ranges. Particles for the global best $\left.\left(G_{\text {Dest }}\right)\right)$ and personal best $\left(P_{\text {Best }}\right)$ are calculated and allocated. Current $G_{\text {Best }}$ value is compared with the previous one and is checked whether the particle's fitness value has improved from the previous iteration or not. After that, in a temp variable $\left(Z_{\text {jtemp }}\right)$ the current position is kept in record and new position and velocity are computed using this current position.

$$
f(i, i t r)=\left\{\begin{array}{l}
\text { false, if particle is having fitness }>G_{\text {Best }}^{\text {ity }-1} \\
\text { true, if particle is having fitness } \leq G_{\text {Best }}^{i t y-1}
\end{array}\right.
$$

$$
\begin{aligned}
& Z_{i}^{i t y+1}=Z_{i}^{i t y}+\beta_{0} e^{-V_{i j}^{2}}\left(Z_{j}^{i t y}-G_{\text {Best }}^{i t y-1}\right)+\alpha e_{i}^{i t y} \\
& V L_{j}^{i t y+1}=Z_{j}^{i t y+1}-Z_{j t e m p}
\end{aligned}
$$

If a particle has an equal or better value of fitness then local search is initiated using FA loop, otherwise, the particle PSO loop is initiated, and PSO works with regular operations for this particle as described in (24) and (25). After this, all particles are evaluated for fitness function and range constraints are examined. If number of iterations are maximum, it ends the hybrid algorithm and the result will be $G_{\text {Best }}$ and its fitness value of the proposed algorithm.

\subsection{TOPSIS Approach}

This problem has many Objectives

optimize $\left[f_{1}(X), f_{2}(X), f_{2}(X), \ldots, f_{n}(X)\right]$

Subjected to $X \in S S$, where $f_{j}(x): R^{n} \rightarrow R$ is the $j$ th objective function, $j=1,2, \ldots, n, n>\mathbb{1}_{v}$ and $S S$ is the search space. As in [6,7], this problem with many objectives is solved by TOPSIS approach for prioritizing the objective functions. The best solution is found without compromising the quality of solution by weighting the objective function. In TOPSIS approach the best solution is 'POIS' and 'NOIS' is the worst solution and are based on Euclidean geometry which is further discussed in step 3. If there are many objectives, individual finest solutions can be found to be present around the best solution without compromising the quality of solution. Improvement in the quality of solution is achieved by TOPSIS approach.

This approach use following steps to find the most appropriate problem solution having many objectives to be satisfied:

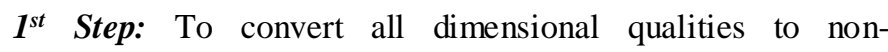
dimensional attributes, create a normalized decision matrix (D.M.).

The matrix elements are given as:

$r_{i j}=\frac{f_{i j}}{\sqrt{\sum_{i=1}^{n_{1}} f_{i j}^{2} j}} \forall i \in n_{1}$ and $j \in n$ 
Where $n_{1}$ is number of feasible solutions and for $j$ th objective, with 'ith' alternate, the value is $f_{i j}$ and ' $n$ ' is number of objective functions.

$2^{\text {nd }}$ Step: If weights for the objectives are required, a normalized decision matrix with weight can be built. If all objectives are equally essential, this phase can be skipped. The matrix's components are written as

$I O_{\mathrm{i} j}=\omega_{j} \times \gamma_{\mathrm{i} j} \forall \forall i \in n_{1}$ and $j \in n$

Where $\omega_{j}$ is the weight of the $j$ th and $\sum_{i=1}^{n} \omega_{j}=1$.

$3^{\text {rd }}$ Step: In this step, best solution is POIS and NOIS is worst solution of each objective individually individual objective, respectively, explained as

$$
\begin{aligned}
& \text { POIS }=\left\{10_{1}^{+}, 10_{2}^{+}, 10_{2, \ldots, n}^{+} 10_{n}^{+}\right\} \\
& \text {NOIS }=\left\{10_{1}^{-}, 10_{2}^{-}, 10_{2}^{-}, \ldots, 10_{n}^{-}\right\}
\end{aligned}
$$

Where,

$$
\begin{aligned}
& 10_{j}^{+}= \\
& \max \left(\mathrm{I}_{0} \mathrm{O}_{\text {ij }}\right) \forall i \text {, } \\
& \text { if benefit is represented by individual objectivepresents a benefit } \\
& \min \left\langle\mathrm{I}_{\mathrm{r}} \mathrm{O}_{\text {ij }}\right\rangle \forall \mathrm{i} \text {, }
\end{aligned}
$$

4th Step: ${ }^{d_{j+}}$ and ${ }^{d_{j-}}$ are Euclidean distances calculated in this step for each possible solution from POIS and NOIS, respectively:

$$
d_{i}^{+}=\sqrt{\sum_{j=1}^{n_{2}}\left(v_{i j}-v_{j}^{+}\right)^{2}}
$$

and

$d_{i j}^{-}=\sqrt{\sum_{j=1}^{n_{2}}\left(v_{i j}-v_{j}^{-}\right)^{2}}$

5th Step: The relatively close index (RCI) is computed for each viable solution calculated as:

$R C I_{i}^{+}=\frac{d_{i}^{-}}{d_{i}^{+}+d_{i}^{-}}$

The most competent solution is possible solution with the highest RCI value and Ranking is carried out according highest value to lowest value.

\subsection{OLRPSD by HFPSO-TOPSIS}

In Two-stage optimization the first stage is to apply HFPSO to get the global best solution of the objective function. As a first step load flow analysis by backward/forward sweep method [10] is performed on the given test system, losses along with power flows and Voltage magnitude are calculated. From the results of basic power flow the initial data is formed. It consists of a population of Reactive power Supporting device (RPSD) sizes and locations that are randomly oriented within lower and upper bounds. The Power flow is performed to get individual best and Global best solutions for positions and sizes. The solution in the previous iteration is compared with this solution. If it is not again, the Particle Swarm optimization loop is initiated. If there is an improvement in the solution observed, then a local search is carried out using the Firefly Algorithm Loop. This process goes on till a global optimum is found or iterations completed are maximum in number. The globally best solution for position and sizing RPSD each objective function is found which is further given as input for Stage II, where the TOPSIS approach is used to prioritize the objective function. Here in this problem, each objective is given the same weightage. The decision matrix is formed using eq.25. The POIS and NOIS is calculated for best and worst solution and then separations measures and Relative closeness index is calculated to rank the best solution. According to weights given to objective functions, the solution may differ as the priority of objective function changes. This procedure is as shown in a flowchart in Figure 1. For HFPSOTOPSIS applied to OLRPSD

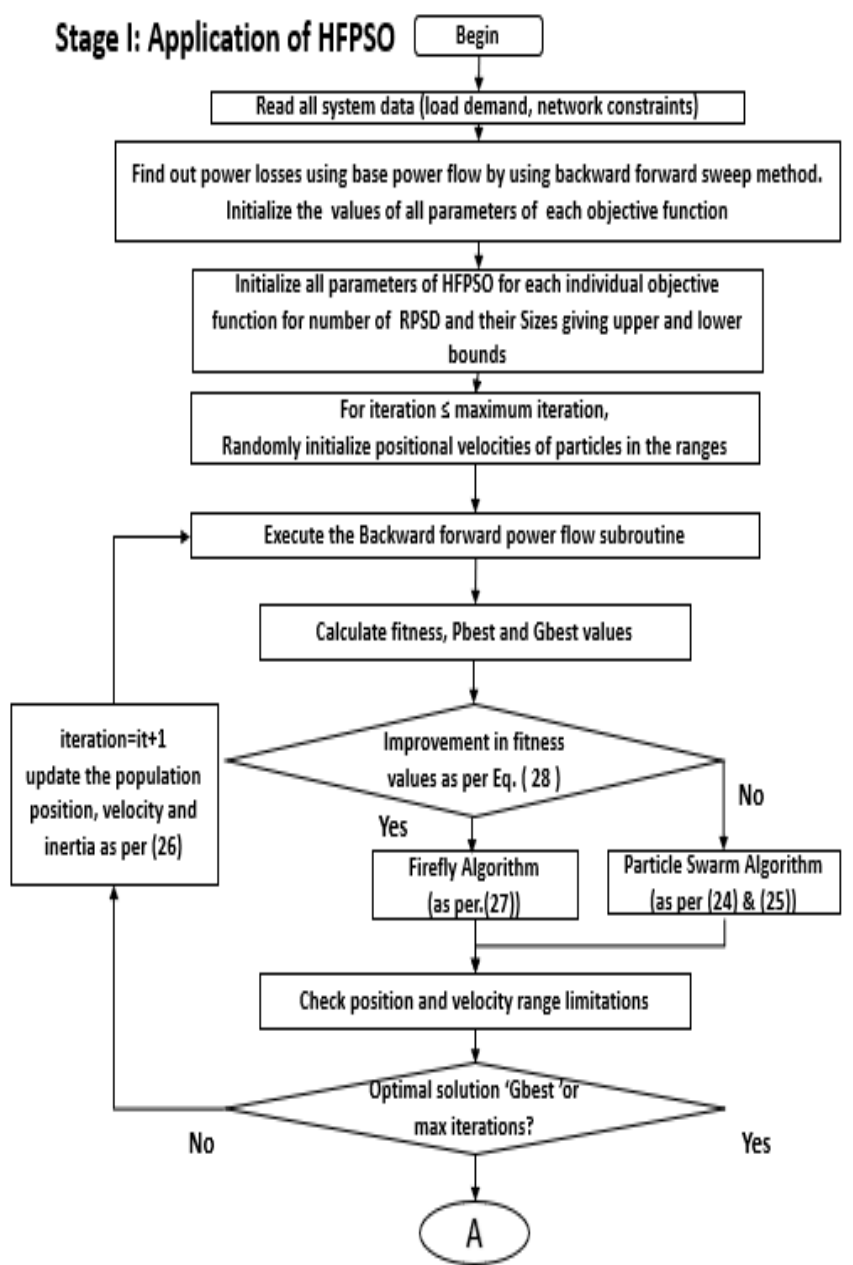

Figure 1. (a): Stage I of Implementation of HFPSO-TOPSIS for OLRPSD 


\section{Stage II: Application of TOPSIS Approach}

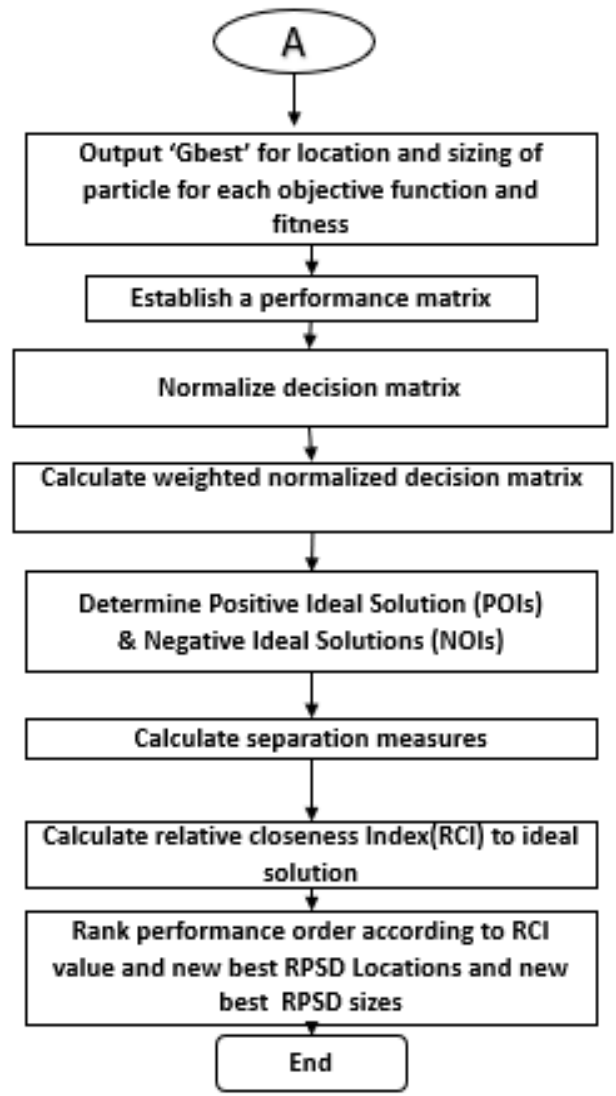

Figure 1. (b): Stage II of Implementation of HFPSO-TOPSIS for OLRPSD

\section{CASE STUDY}

The "modified radial distribution system IEEE 33 bus system" [23] as shown in Figure 2, having voltage level of $12.66 \mathrm{kV}$. 3.715 MW and 2.3 MVAr is the maximum active and reactive power at maximum load condition [23, 24]. Load flow using Backward/forward sweep method at maximum load is carried out for this system. The real power loss obtained is as "210.0897 kW"and reactive power losses are "143.027 kVAr" $[23,24]$ respectively.

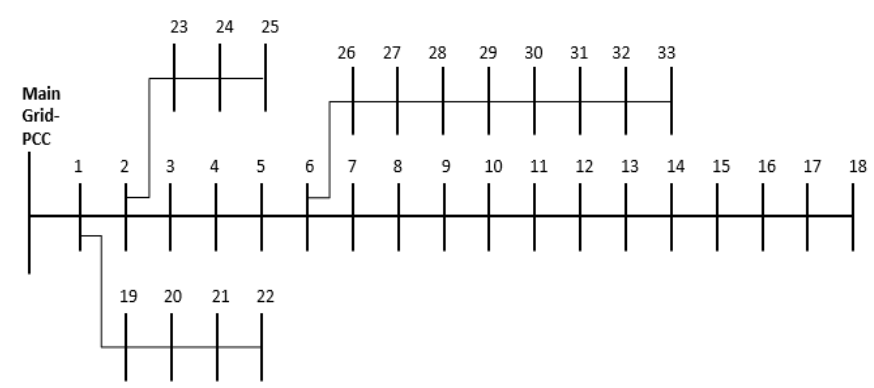

Figure 2. Modified "IEEE 33 bus system" radial distribution network

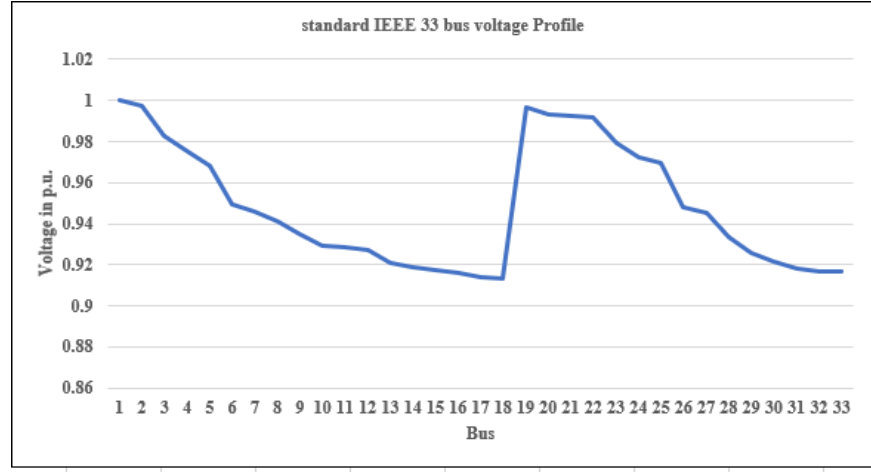

Figure 3. Voltage profile of standard IEEE 33 bus radial distribution system (base case).

As can be seen in Figure. 3. The magnitude of the voltage is determined by load flow. The lowest voltage level is 0.910 p.u. is at bus 18 , and the minimum voltage stability index is 0.6686 at the same location

\section{RESULTS AND DISCUSSION}

The proposed algorithm was implemented and evaluated using MATLAB $®$ programming on a PC with an Intel $®$ CORE TM i5-7200U CPU running at $2.50 \mathrm{GHz}$ and $8.00 \mathrm{~GB}$ of RAM. The simulations are run under maximum load using IEEE standard 33-bus RDS test system.

\subsection{Optimal Location of Capacitors:}

In Table 1. Results are tabulated, for optimal location of capacitors considering all objectives.

Table 1: optimal location for fixed capacitors.

\begin{tabular}{|c|c|c|c|c|c|c|c|}
\hline RPSD & Algo & @ Bus & $\begin{array}{l}\text { Size } \\
\text { kVAr }\end{array}$ & $f 1$ & $f 2$ & $\begin{array}{c}f 3 \\
\text { SMVArh }\end{array}$ & f4 \\
\hline Base case & $\mathrm{NA}$ & $\mathrm{NA}$ & $\mathrm{NA}$ & 0.11 & 210 & 17.92 & 0.67 \\
\hline \multirow{2}{*}{$\begin{array}{c}\text { Fixed } \\
\text { Capacitors }\end{array}$} & $\mathrm{ACO}[8]$ & $9,22,25$ & $\begin{array}{l}645, \\
719, \\
665\end{array}$ & 0.05 & 162 & NA & 0.79 \\
\hline & $\begin{array}{l}\text { HFPSO- } \\
\text { TOPSIS }\end{array}$ & $6,9,13$ & $\begin{array}{c}1200 \\
542 \\
264\end{array}$ & 0.05 & 140 & 2.64 & 0.88 \\
\hline
\end{tabular}

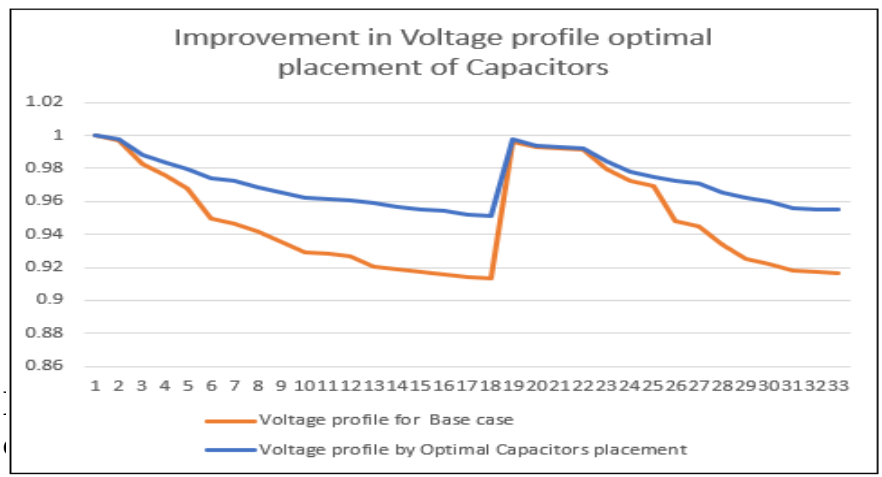

Figure 4. Improvement in Voltage profile by optimal Fixed capacitor location 
As seen from Figure.4. Voltage profile is improved as observed minimum voltage is 0.95 p.u.

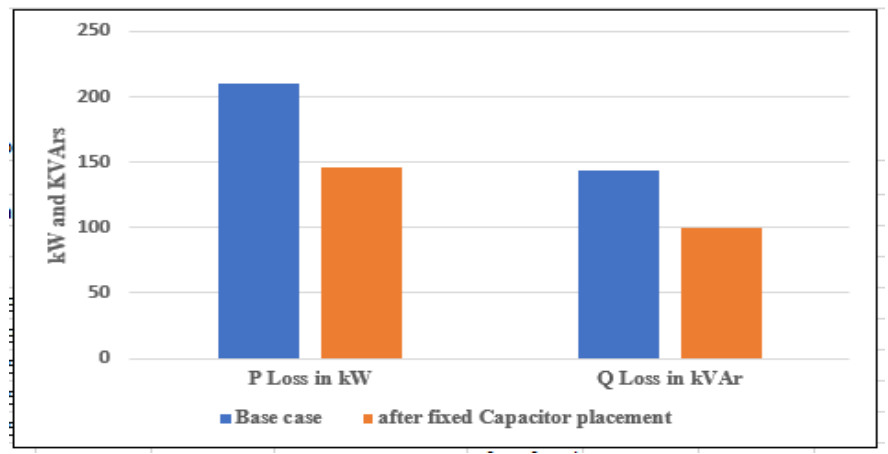

Figure 5. Comparison with base case, minimization of Power loss by optimal capacitor location.

As evident form Figureure.5. By optimal location of Capacitors by HFPSO-TOPSIS, Losses are also reduced by 32 $\%$ as compared to $27 \%$ by ACO.

\subsection{Optimal Location of only D-STATCOM and PV- D- STATCOM system:}

D-STATCOM, in conjunction with a distributed generator, can provide and absorb reactive power while maintaining a voltage of 1.0 p.u. For proper location of D-STATCOM with DG at bus.no.30, all objectives, as well as operational and constraints are evaluated. It is observed that after placing DSTATCOM with DG at this location, the voltage profile is improved substantially. The HFPSO-TOPSIS results for OPRPCD are reported in Table 2. Figure 6 depicts improvement in voltage profile using only D-STATCOM, while Figure 7 depicts voltage profile improvement using both D-STATCOM and DG. Loss minimization by only DSTATCOM's optimal location and optimally located DSTATCOM with DG is in seen in Figure.8.Losses are reduced more by when D-STATCOM is associated with DG and optimally located.

Table 2: Results for optimal location of D-STATCOM

\begin{tabular}{|c|c|c|c|c|c|c|c|}
\hline RPSD & Algo & (@) Bus & $\begin{array}{c}\text { Size } \\
\text { kVAr }\end{array}$ & $f 1$ & $f^{2}$ & $\begin{array}{c}f 3 \\
\text { SMVArh }\end{array}$ & f4 \\
\hline Base case & $\mathrm{NA}$ & $\mathrm{NA}$ & $\mathrm{NA}$ & 0.11 & 210 & 17.92 & 0.67 \\
\hline \multirow[b]{2}{*}{\begin{tabular}{|c} 
only \\
DSTATC \\
OM
\end{tabular}} & HSA[11] & 12 & 1150 & $\mathrm{NA}$ & 143 & $\mathrm{NA}$ & NA \\
\hline & $\begin{array}{l}\text { HFPSO- } \\
\text { TOPSIS }\end{array}$ & 30 & 962 & $\mathrm{NA}$ & 148 & 8.32 & 0.7 \\
\hline \multirow{2}{*}{\begin{tabular}{|c|} 
D- \\
STATCo \\
M with DG \\
$1500 \mathrm{~kW}$
\end{tabular}} & DLF [9] & 30 & 1,000 & 0.08 & 86 & NA & 0.68 \\
\hline & $\begin{array}{l}\text { HFPSO- } \\
\text { TOPSIS }\end{array}$ & 30 & 1,000 & 0.08 & 78 & 5.19 & 0.8 \\
\hline
\end{tabular}



Figure 6. Voltage profile improvement with optimal location of only D-STATCOM at bus.no.30 for reactive power supporting.

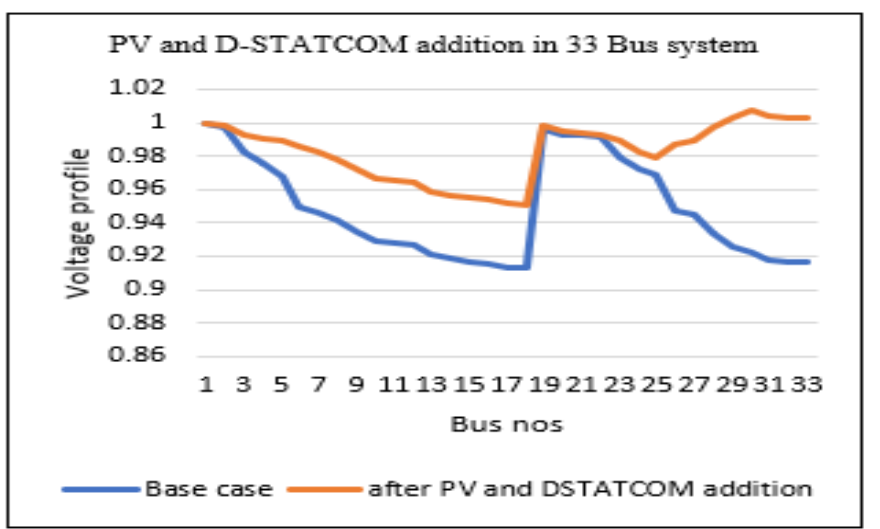

Figure 7. Improvement in Voltage profile of IEEE 33 Bus radial system after optimally placing PV-D-STATCOM at bus no. 30 .

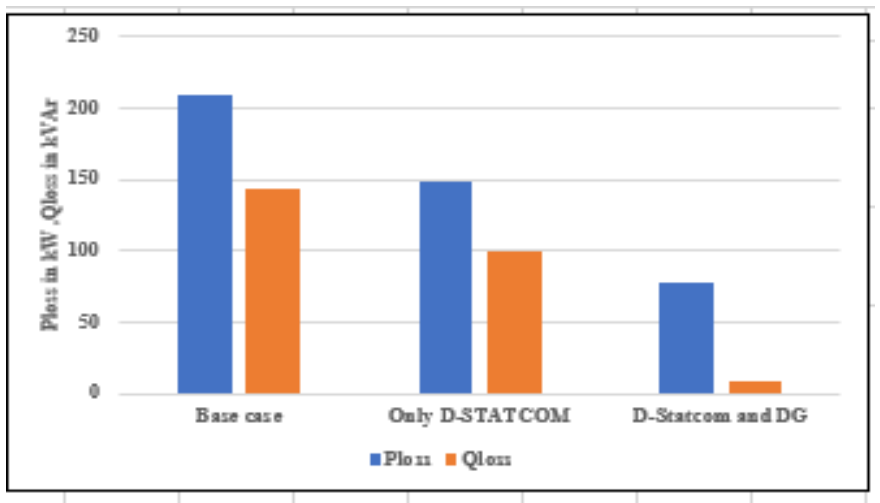

Figure 8. Minimization of losses by Optimally placing DSTATCOM and of D-STATCOM with DG.

\subsection{Optimal Location of DGs:}

Table 3 below gives results of objective functions attained values for optimal location of DGs. Optimization using HFPSO-TOPSIS is carried out and objectives are considered simultaneously for DG location and sizing for getting a more practical, realistic and economical solution. 
Table 3: Optimal Location of Distributed generation

\begin{tabular}{|c|c|c|c|c|c|c|c|}
\hline RPSD & Algo & $\begin{array}{c}\text { @ Bus } \\
\text { location of } \\
\text { DG }\end{array}$ & $\begin{array}{c}\text { DG } \\
\text { Size } \\
\mathbf{k W}\end{array}$ & fl & f in kW & $\begin{array}{c}\text { f3 } \\
\text { sMVArh }\end{array}$ & f4 \\
\hline \multirow{6}{*}{ DG } & NA & NA & NA & 0.11 & 210 & 17.92 & 0.67 \\
\cline { 2 - 8 } & GA[ ] & $6,13,24,30$ & $\begin{array}{c}643, \\
857, \\
857,738\end{array}$ & 0.0115 & 71 & NA & 0.87 \\
\cline { 2 - 8 } & HFPSO- & & $\begin{array}{c}1200, \\
900,\end{array}$ & 0.06 & 70 & 5.19 & 0.93 \\
\hline
\end{tabular}

The sizes of DGs considered are $1200 \mathrm{~kW}, 900 \mathrm{~kW}, 600 \mathrm{~kW}$, $1300 \mathrm{~kW}$. It is observed that there is improvement in voltage profile as compared to base case as seen in Figure. 9 with voltage level of $0.947 \mathrm{p}$.u to be minimum. The power losses are reduced to $65 \%$ as is observed from Figure. 10 .

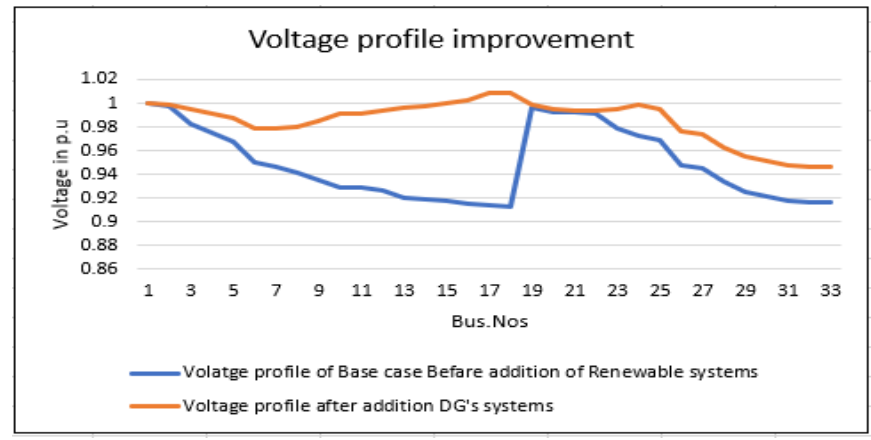

Figure 9. Voltage profile improvement by optimally Placing Distributed generation sources.

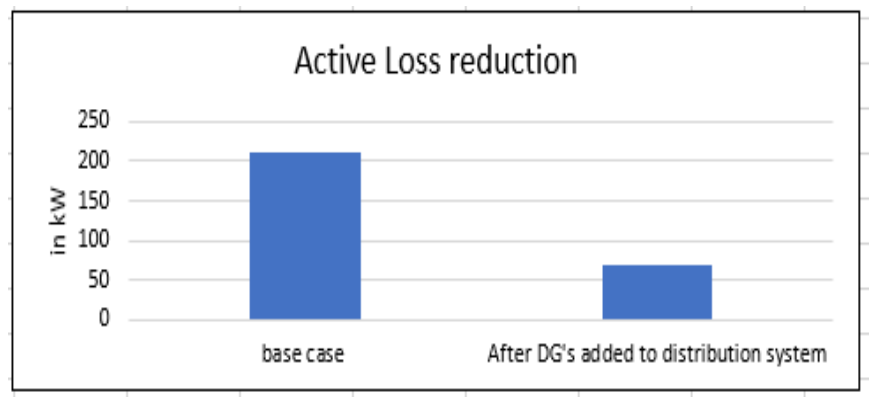

Figure 10. Minimization of losses by optimal Location of Distributed generation for reactive power support.

\subsection{Optimal location of batteries}

If Battery Energy storage system (BESS) is not properly sized and located in power system than it can cause system disturbances like over voltages, low voltages and also highpower losses. All objectives along with constraints are considered. High voltage sensitivity shows that the large change in voltage at that bus may occur for even small change in voltage. When energy storage is placed at this optimum location then it avoids major change in voltages due to small changes in load. Table 4 shows the results of OPRPCD (Batteries and DG). The modified topology of IEEE 33 bus radial system after DG and Batteries are placed is depicted in
Figure 11. Improved voltage profile is as seen in Figure.12. The optimal bus location is found to be at bus.no. 14,18,24,32.

Table 4: Results for optimal location of Batteries

\begin{tabular}{|c|c|c|c|c|c|c|c|}
\hline RPCD & Algo & @ Bus & $\begin{array}{c}\text { Size } \\
\text { kVAr }\end{array}$ & $f 1$ & $f 2$ & $\begin{array}{c}f 3 \\
\text { S/MVArh }\end{array}$ & $f 4$ \\
\hline Base case & NA & NA & NA & 0.11 & 210 & 17.92 & 0.67 \\
\hline $\begin{array}{c}\text { Battery } \\
\text { with DG }\end{array}$ & $\begin{array}{c}\text { GAMS } \\
{[25]}\end{array}$ & $7,8,24,25$ & $\begin{array}{c}\text { DG in } \mathrm{kW} \\
1350.2,1499 \\
446.73,418.68 \\
\text { and } 1300 \\
\mathrm{kWh} \text { battery } \\
\text { at each } \\
\text { location }\end{array}$ & 0.04 & NA & NA & NA \\
\cline { 2 - 8 } & $\begin{array}{c}\text { HFPSO- } \\
\text { TOPSI } \\
\mathrm{S}\end{array}$ & $14,18,24,32$ & $\begin{array}{c}\text { DG in } \mathrm{kW} \\
1200,900,600 \\
\text { and Battery } \\
\text { of SOC } \\
\text { Max= } 800 \mathrm{kWh}\end{array}$ & 0.03 & 17 & 0.93 & 0.9 \\
\hline
\end{tabular}

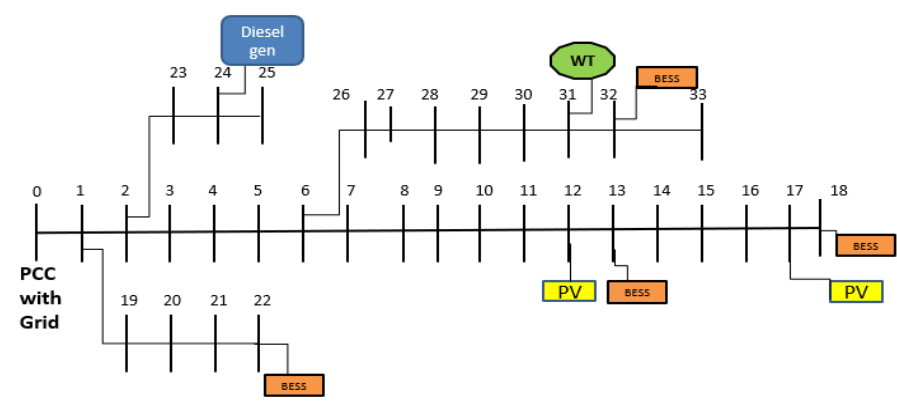

Figure 11. DG's sources and BESS optimally placed in ithe test system for reactive power support.

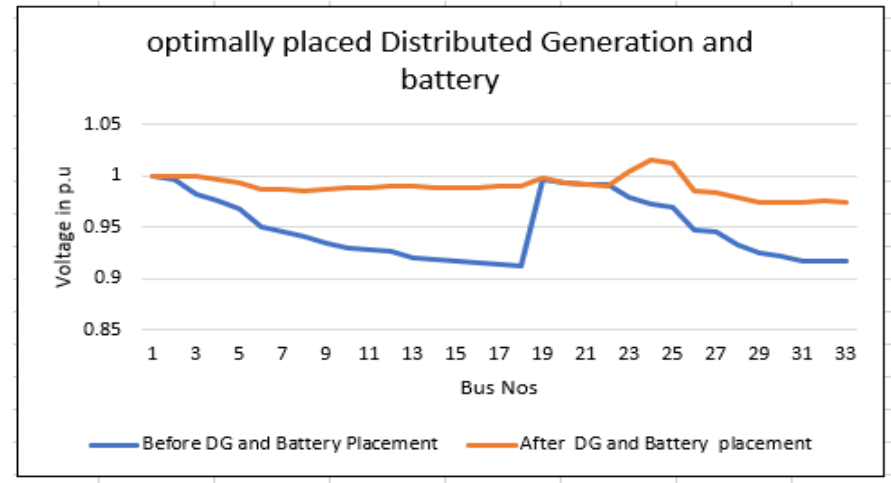

Figure 12. Volatge profile improvement as compared to base case by optimal location of DG's and Batteries.

\subsection{Optimal Location of EV charging points}

If there are any voltage violations into the grid, instead of dumb charging through active power absorption only, electric vehicle can inject reactive power into the grid to maintain the voltage and this is called as power factor control mode of charging. The voltage in the system is improved when Electric Vehicles are charged in power factor control mode. Therefore, the Charging stations have to be optimally positioned in system. Table 5 gives the data considered for EV charging 
stations optimal location in the test system. All 4 objective functions considered. Base case without any Charging stations (ChS's) and Charging Points (ChP's) is considered as 'Case A'. Three charging stations one in each sub-feeder is optimally placed with minimum number of ChP's. This increases the real power load to from $3715 \mathrm{~kW}$ to $6640 \mathrm{~kW}$ and losses also increase from $203 \mathrm{kw}$ to $576 \mathrm{~kW}$. This condition is considered as 'case B' and When Optimization Tool is used and EV charging stations are optimally placed the scenario is considered as 'case C'. Table 6 gives the results for optimal location of EV ChS's using HFPSO-TOPSIS method are compared with results obtained from Teaching Learning algorithm (TLBO) and Particle Swarm Optimization (PSO) [26].

Table 5: Data considered for EV charging stations

\begin{tabular}{|l|l|l|l|l|l|}
\hline \multirow{2}{*}{ EV Type } & $\begin{array}{l}\text { EV Power } \\
\text { Rating } \\
(\mathbf{k W})\end{array}$ & \multicolumn{2}{|l|}{ No of ChPs } & \multicolumn{2}{l|}{$\begin{array}{l}\text { Rating of ChS } \\
(\mathbf{k W})\end{array}$} \\
\cline { 3 - 6 } & Min & Max & Min & Max \\
\hline $\begin{array}{l}\text { Chevrolet } \\
\text { VOLT }\end{array}$ & 2.2 & 25 & 35 & 55 & 77 \\
\hline $\begin{array}{l}\text { CHANG } \\
\text { AN } \\
\text { YIDONG }\end{array}$ & 3.75 & 20 & 30 & 75 & 112.5 \\
\hline $\begin{array}{l}\text { Tesla } \\
\text { Model X }\end{array}$ & 12 & 15 & 25 & 195 & 325 \\
\hline BMW i3 & 44 & 10 & 20 & 440 & 880 \\
\hline $\begin{array}{l}\text { SAE } \\
\text { J1772 } \\
\text { Standard }\end{array}$ & 7 & & & & \\
\hline \begin{tabular}{l} 
Total Power Rating of ChS (kW) \\
\hline
\end{tabular} & 30 & 40 & 210 & 280 \\
\hline
\end{tabular}

Table 6: Optimal location of EV ChS's by HFPSOTOPSIS.

\begin{tabular}{|l|l|l|l|l|l|}
\hline Case & Algorithm & $\begin{array}{l}\text { EV CS's } \\
\text { location }\end{array}$ & Ploss & $\begin{array}{l}\text { VSI } \\
\text { min }\end{array}$ & $\begin{array}{l}\text { Vmin } \\
\text { (p.u) }\end{array}$ \\
\hline A & - & - & 203 & 0.666 & 0.903 \\
\hline B & - & - & 576 & 0.496 & 0.840 \\
\hline C & TLBO & $2 / 19 / 25$ & 295.6 & 0.649 & 0.898 \\
\hline & PSO & $2 / 19 / 25$ & 292 & 0.649 & 0.898 \\
\hline & $\begin{array}{l}\text { HFPSO- } \\
\text { TOPSIS }\end{array}$ & $2 / 19 / 21$ & 248 & 0.69 & 0.90 \\
\hline
\end{tabular}

Table 6, shows that, apllication of HFPSO-TOPSIS, gives the optimal location of EV ChS's that minimizes the active power losses in the system. It is observed that by implementing HFPSO-TOPSIS approach these losses are reduced by $57 \%$ whereas losses are reduced by only $50 \%$ by other methods.

\section{CONCLUSION AND FUTURE}

\section{SCOPE}

The results it is evident that OLRPSD at distribution system is very essential and leads to minimization of losses, voltage profile improvement, maximized techno economic benefits to consumer and system operator while improving overall system performance and reliability. This problem is a multi-objective and complex problem which requires multi objective Multicriteria decision-making (MOMCDM) approach, like HFPSOTOPSIS.

In this work, strong points of "Firefly and particle swarm optimization" are properly utilized "HFPSO-TOPSIS" approach is successfully applied to OLRPSD and its sizing. This technique can optimize many objectives successfully and simultaneously. The financial benefits due to reactive power support cost minimization and power quality improvement is highlighted feature achieved by this approach. It is observed that with reactive power support the voltage profile is improved a lot along with power quality is also improved. Reactive power compensating devices like capacitors, DSTATCOM-PV system, Distributed Generators like Wind energy conversion system, PV system, Diesel Generators, Batteries are not only placed but also properly sized for reactive power supporting. This paper proposes application of HFPSO-TOPSIS for recently introduced reactive power compensating devices like EV Charging stations also.

This method can be successfully implemented for more complex problems having many technical and economic objectives to be satisfied simultaneously, such as optimal location of transformers in distribution system, optimal bidding, optimal scheduling simultaneously considering many objective functions at same time with preference or prioritizing particular objective functions.

\section{REFERENCES}

[1] https://energy.economictimes. indiatimes.com/news/renewable/in dia-to-have-450-gw-renewable-energy-by-2030-president.

[2] https://energy.economictimes. indiatimes.com

[3] Kavitha K and Neela R, "Optimal allocation of multi-type FACTS devices and its effect in enhancing system security using BBO', Journal of electrical systems and Information technology, 2018. Pp777-783.

[4] Dipesh Gaur and Lini Mathew, "Optimal location of FACTS devices using optimization techniques: A review" IOP Conf. Ser.: Mater. Sci. Eng. 331(2018) 012023.2018.

[5] D. Sattianadan, M. Sudhakaran, S.S. Dash, K. Vijayakumar and Bishnupriya Biswal, "Power Loss Minimization by the Location of DG in Distribution System Using PSO", Proc. of Int. Conf. on Front. of Intell. Comput., AISC 199, pp. 497-504.springerverlag Berlin Heidelberg 2013.

[6] M.M. Aman, G.B. Jasmon, A.H.A. Bakar, H. Mokhlis, "A new approach for optimum DG location and sizing based on voltage stability maximization and minimization of power losses", Energy Conversion and Management 70 (2013) 202-210.

[7] Dinakara Prasasd Reddy P, V.C. Veera Reddy, T. Gowri Manohar, "Optimal renewable resources placement in distribution networks by combined power loss index and whale optimization algorithm", Journal of Electrical Systems and Information Technology, (2017), pp. 175-191

[8] Adel Ali Abou El-Ela, Ragab A. El-Sehiemy, Abdel-Mohsen Kinawy, Mohamed Taha Mouwafi "Optimal capacitor location in distribution systems for power loss reduction and voltage profile improvement", IET Generation, Transmission \& Distribution,2016, Vol. 10, Iss. 5, pp. 1209-1221 
[9] T.Yuvaraja, ,K.R.Devabalajia, K.Ravia, "Optimal location and sizing of DSTATCOM using Harmony Search algorithm", International Conference on Alternative Energy in Developing Countries and Emerging Economies,2015,Elsevier, Energy Procedia 79 ( 2015 )pp. 759 - 765 .

[10] Srinivas Bhaskar Karanki, David Xu and Bala Venkatesh, Birendra N. Singh, "Optimal Location of Battery Energy Storage Systems in Power Distribution Network for Integrating Renewable Energy Sources", IEEE2013.

[11] Ahmed Alzahrani, Hussain Alharthi and Muhammad Khalid, "Minimization of Power Losses through Optimal Battery Location in a Distributed Network with High Penetration of Photovoltaics" Energies 2020, 13, 140.

[12] Ponnam Venkata K Babu*‡, K. Swarnasri, "Multi-Objective Optimal Allocation of Electric Vehicle Charging Stations in Radial Distribution System Using Teaching Learning Based Optimization" International Journal of Renewable Energy Research, Vol.10, No.1, March, 2020.

[13] Moupuri Satish Kumar Reddy, K.Selvajyothi "Optimal Location of Electric Vehicle Charging Stations in Radial Distribution System along with Reconfiguration", 1st International Conference on Energy, Systems and Information, 2019, IEEE.

[14] A. Aguila Tellez, G. Lopez, I. Isaac,J. W. Gonz alez,"Optimal reactive power supporting in electrical distribution systems with distributed resources" Review. Heliyon (2018).

[15] H. Haghighat and S. Kennedy, "A Model for Reactive Power Pricing and Dispatch of Distributed Generation ", IEEE PES General Meeting, Minneapolis, MN, USA, 2010.

[16] Ruoyang Li, Qiuwei Wu and Shmuel S. Oren," Distribution Locational Marginal Pricing for Optimal Electric Vehicle Charging Management" IEEE TRANSACTIONS ON POWER SYSTEMS, VOL. 29, NO. 1, JANUARY 2014203.

[17] Chitransh Shrivastava, Manoj Gupta, Dr. Atul Koshti, "Review of Forward \& Backward Sweep Method for Load Flow Analysis of Radial Distribution System" International Journal of Advanced Research in Electrical, Electronics and Instrumentation Engineering, Vol. 4, Issue 6, June 2015.

[18] Gai-Ge Wang; Suash Deb; Leandro dos S. Coelho, "Elephant Herding Optimization",3rd International Symposium on Computational and Business Intelligence (ISCBI),Bali,Indonesia, 18 January 2016

[19] Nand Kishor Meena, Sonam Parashar, Anil Swarnkar,Nikhil Gupta and Khaleequr Rehman Niazi,"Improved Elephant Herding Optimization for Multiobjective DER Accommodation in Distribution Systems" ,IEEE Transactions On Industrial Informatics, Vol. 14, No. 3, March 2018.

[20] Pushpendra Singh, Nand K. Meena Jin Yang*, Eduardo VegaFuentes, Shree Krishna Bishnoi, "Multi-criteria decision making monarch butterfly optimization for optimal distributed energy resources mix in distribution networks", Applied Energy 278 (2020).

[21] Mesut E. Baran and Felix F. Wu 'Network reconfiguration in distribution systems for loss reduction and load balancing', presented at IEEE /PES 1988 Summer meeting, Portland, Oregon, July 24-29,1988,Printed in 1989.

[22] M. A. Kashem, V. Ganapathy, G. B. Jasmon \& M. Buhari, "A novel method for loss minimization in distribution networks," in International Conference on Electric Utility Deregulation and Restructuring and Power Technologies (DRPT 2000), 2000.

[23] Bharat Singh, Satyaveer Singh Rawat, "Optimal Location of DG with Battery Energy Storage in Distribution Network for Power loss Minimization using Combined Dispatch \& Combined PLS Strategy "International Journal of Engineering and Advanced Technology (IJEAT), Volume-9 Issue-5, June 2020.

[24] P. V. K. Babu and K. Swarnasri,"Multi-Objective Optimal Allocation of Electric Vehicle Charging Stations in Radial
Distribution System Using Teaching Learning Based Optimization "International Journal of Renewable Energy research, Vol.10, No.1, March, 2020.

[25] M. H. Moradi and M. Abedinie, "A combination of genetic algorithm and particle swarm optimization for optimal DG location and sizing in distribution systems," in Proc. Conf. Proc. IPEC, Singapore, 2010, pp. 858-862.

[26] K.Divya , S.Srinivasan, "Placing And Sizing of DG In Radial Distribution System And Identifying Fault Location In Distribution System Integrated With Distributed Generation" International Research Journal of Engineering and Technology, Volume: 02 Issue: 09,pp:440-449,Dec-2015.

[27] Jose L. Mart'inez-Ramos, Alejandro Marano-Marcolini, Francisco P. Garc'ia-L'opez, Fernando Almagro-Yravedra, Ahmet Oneny, Yeliz Yoldasy, Mounir Khiatz, Leila Ghomriz, Nunziatina Fragalex,"Provision of Ancillary Services by a Smart Microgrid: An OPF Approach", 2018 International Conference on Smart Energy Systems and Technologies, IEEE, (SEST),Sevilla, Spain,10-12 Sept. 2018.

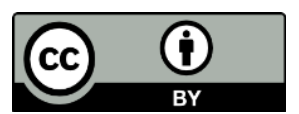

(C) 2021 by the Prof. Kalyani Kurundkar, Dr. G. A. Vaidya. Submitted for possible open access publication under the terms and conditions of the Creative Commons Attribution (CC BY) license (http://creativecommons.org/licenses/by/4.0/). 